\title{
New Host and Ocean Records for the Parasitic Copepod Bobkabata kabatabobbus (Lernaeosoleidae: Poecilostomatoida) ${ }^{1}$
}

\author{
George W. Benz, ${ }^{2,3}$ Kazuya Nagasawa, ${ }^{4}$ and feremy Wetmore $^{3,5}$
}

\begin{abstract}
The parasitic copepod Bobkabata kabatabobbus Hogans \& Benz is reported for the first time from the Pacific Ocean and from the darkfin sculpin, Malacocottus zonurus (Psychrolutidae: Scorpaeniformes). Based on five specimens, several morphological features are reported for the first time for $B$. $k a b a-$ tabobbus, including a second protuberance on the cephalothorax, a pair of vestigial legs on the neck, and two dark-staining sclerites on the trunk that may represent body segment boundaries or interpodal bars.
\end{abstract}

Bobkabata Hogans \& Benz, 1990, is one of two monotypic genera within Lernaeosoleidae Yamaguti, 1963 (Poecilostomatoida: Copepoda). Until this report, B. kabatabobbus Hogans \& Benz, 1990, was known only from two collections consisting of three individuals taken from the pallid sculpin, Cottunculus thomsoni (Günther, 1882) (Psychrolutidae: Scorpaeniformes) in the western North Atlantic (Hogans and Benz 1990, Benz and Braswell 1998). Herein we present the first record of $B$. kabatabobbus from the Pacific Ocean as well as a new host fish for this parasite. We also provide new information regarding the morphology of B. kabatabobbus.

\section{MATERIALS AND METHODS}

A total of five $B$. kabatabobbus adult females was collected from two formalin-fixed darkfin

${ }^{1}$ Manuscript accepted 7 November 2001.

2 Corresponding author: Tennessee Aquarium, One Broad Street, Chattanooga, Tennessee 37401 (phone: 706-694-4666; fax: 706-694-3957; E-mail: GWB@tennis. org).

${ }^{3}$ Tennessee Aquarium Research Institute, 5385 Red Clay Road, Cohutta, Georgia 30710.

${ }_{4}$ National Research Institute of Aquaculture, Nikko Branch, Fisheries Research Agency, Nikko, Tochigi 3211661, Japan.

5 Department of Biology, Southern Adventist University, P.O. Box 370, Collegedale, Tennessee $37315-$ 0371 .

Pacific Science (2002), vol. 56, no. 3:259-262

(C) 2002 by University of Hawai' $i$ Press

All rights reserved sculpins, Malacocottus zonurus Bean, 1890 (Psychrolutidae: Scorpaeniformes). One host, $114 \mathrm{~mm}$ standard length, was captured 24 March 1976 in a fishing trawl at $360 \mathrm{~m}$ in the western North Pacific Ocean east of Cape Erimo, Hokkaido $\left(42^{\circ} 1.9^{\prime} \mathrm{N}, 143^{\circ} 44.4^{\prime} \mathrm{E}\right)$. This host was infected with one $B$. kabatabobbus adult female that was attached at the base of the soft-rayed portion of the dorsal fin. This intact specimen has been deposited in the National Science Museum, Tokyo, Japan (NSmT-Cr 14164). The second host was captured 4 April 1984 in a fishing trawl at an unknown depth in the western North Pacific Ocean east of Cape Erimo, Hokkaido $\left(42^{\circ} 18^{\prime} \mathrm{N}, 144^{\circ} 2.2^{\prime} \mathrm{E}\right)$. This host was infected with four B. kabatabobbus adult females, one at the base of the spiny-rayed portion of the dorsal fin and three along the base of the soft-rayed portion of the dorsal fin. One intact specimen and the posterior portion of a second specimen from this collection have been deposited in the NSMT (NSMT-Cr 14165 and NSMT-Cr 14166, respectively).

Bobkabata kabatabobbus is a mesoparasite (sensu Kabata 1979), and all five specimens reported here were found embedded in the musculature of the hosts with only a short portion of the thoracic "neck" and the horseshoelike posterior of the body protruding. After they were dissected from their hosts, the copepods were studied using light (LM) and scanning electron microscopy (SEM). For LM studies copepods were cleared and stained in a solution of lactic acid and lignin pink and subsequently examined using the wooden slide technique of Humes and Good- 
ing (1964). One specimen was examined using SEM. This specimen was prepared for gold-palladium sputter coating by placing it in $100 \%$ ethanol (two changes, $1 \mathrm{hr}$ each) followed by immersion in a small volume of hexamethyldisilazane (15 $\mathrm{min})$. Before mounting on a metal stub with two-sided sticky tape, drying was achieved by placing the specimen under a slight vacuum to remove the hexamethyldisilazane. Illustrations were prepared with the aid of a camera lucida (LM) or they were drawn with some interpretation from SEM micrographs. Specimens were measured using an eyepiece graticule (LM) and measurements in millimeters are reported as the mean followed in parentheses by the standard deviation, range, and sample size. Conventions for measurements are shown in Figure $1 A$. Terminology regarding copepod morphology follows Huys and Boxshall (1991). Host systematics follows Nelson (1994).

\section{RESULTS AND DISCUSSION}

All of the specimens of $B$. kabatabobbus reported here generally matched the descriptions of the species provided by Hogans and Benz (1990) and Benz and Braswell (1998). However, some specimens exhibited features not previously observed, and based on these new specimens the following additional information on the species is provided: total length, $9.46( \pm 1.515,8.32-12.06,5)$; head length, $2.08( \pm 0.232,1.80-2.42,5)$; head width, 1.77 ( $\pm 0.364,1.35-2.17,5)$; primary head protuberance width, $0.49( \pm 0.125$, $0.37-0.62,3)$; neck length, $2.74( \pm 0.558$, $2.26-3.69,5)$; neck width, $0.50( \pm 0.144$, $0.37-0.74,5)$; trunk length, $4.64( \pm 0.78,4.1-$ $5.95,5)$; trunk width, $4.712( \pm 1.41,3.4-6.97$, 5); trunk lobe width, $2.05( \pm 0.596,1.39-3.44$, 10). One specimen (NSMT-Cr 14165) possessed a second cephalothoracic protuberance, $1.23 \mathrm{~mm}$ in diameter, just posterior to its antennae (see Figure $1 B-D$ ). The intact antennae of specimens each possessed a small medial basal seta (Figure $1 E$ ). A pair of vestigial legs (Figure $1 F$ ) located ventrally in the anterior region of the neck (Figure $1 A$ ) was observed on four of the five specimens. The basal portions of the right and left vestigial legs were connected by a thin, dark-staining sclerite (? = interpodal bar) that was not raised above the body surface. Each leg consisted of an unsegmented exopod and endopod (Figure 1F). All five specimens also exhibited two thin, dark-staining sclerites on the ventral surface of the trunk posterior to the aforementioned legs that may represent segment boundaries or interpodal bars (see Figure $1 A$ ). No legs were associated with these sclerites; however, each (as well as the interpodal bar [?] associated with the vestigial legs) had bands of striated muscle attached to them (see Figure $1 A$ ) that were visible through the cleared exoskeleton. If these sclerites are interpodal bars then B. kabatabobbus may possess three pairs of legs at some point in its ontogeny. The caudal rami of the specimen observed using SEM each possessed six setae: one long and stout and five short and thin (Figure $1 G$ ). Specimen NSMT-Cr 14166 possessed one multiseriate egg sac.

The two known hosts of $B$. kabatabobbus each have wide distributions, with Cottunculus thomsoni found on both sides of the North Atlantic Ocean at depths of between 182 and $1462 \mathrm{~m}$ (Scott and Scott 1988) and Malacocottus zonurus found on both sides of the North Pacific Ocean at depths between 400 and $1980 \mathrm{~m}$ (Yabe 1984). Thus we should expect that future collections of these host species may expand the known range of $B$. kabatabobbus throughout these regions. Furthermore, because $C$. thomsoni and $M$. zonurus are each psychrolutids (Psychrolutidae), we might also expect that other members of this family serve as hosts for B. kabatabobbus. Finally, in spite of the aforementioned morphological and host differences between the Bobkabata specimens collected from the Atlantic and Pacific Oceans, we herein act conservatively by assigning the five Bobkabata specimens collected from the Pacific Ocean to B. kabatabobbus. Additional collections of Bobkabata representatives are necessary to thoroughly assess these variations regarding the possibility that the Pacific and Atlantic Oceans are home to different Bobkabata species. 

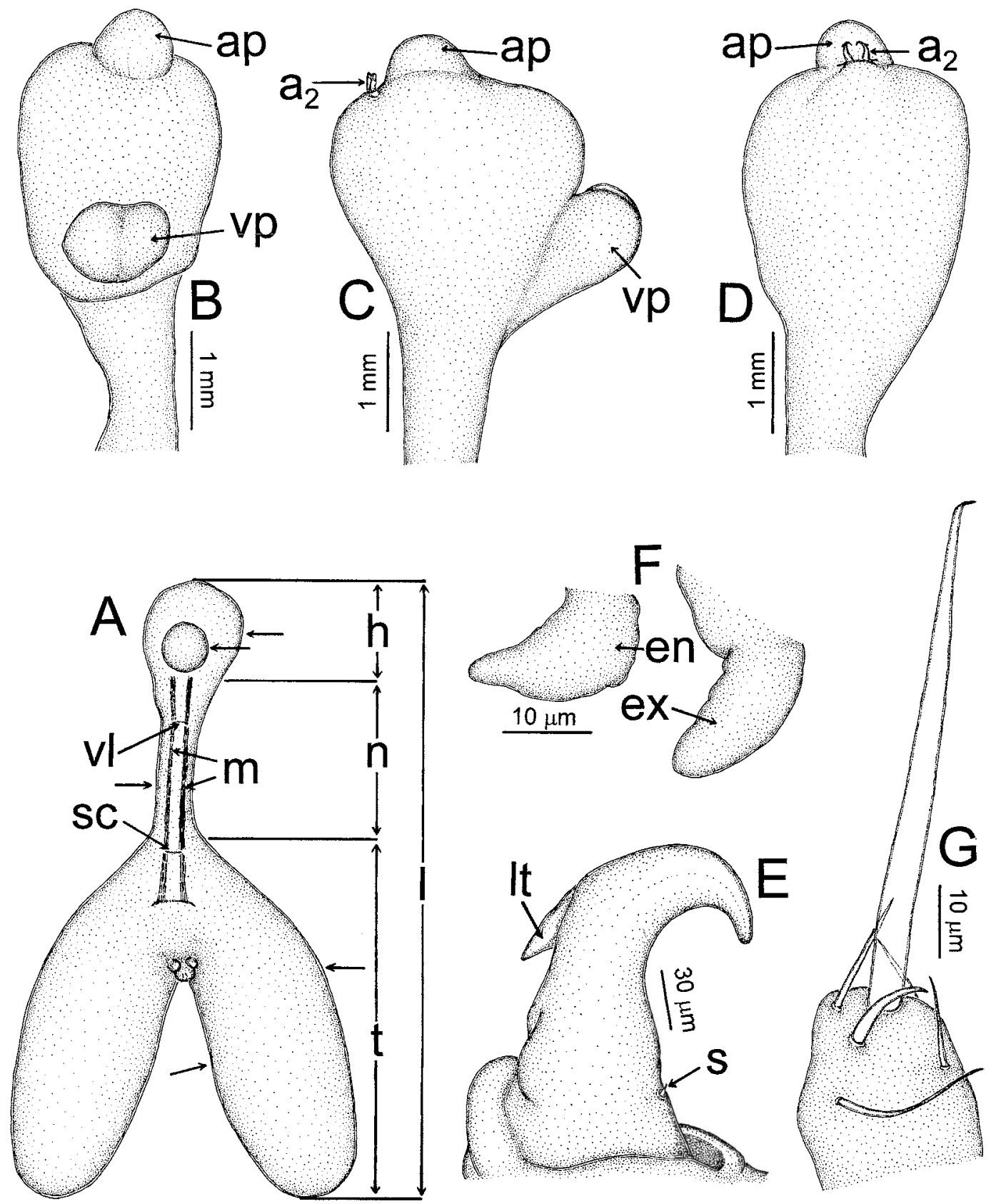

Figure 1. Bobkabata kabatabobbus. Adult females. $A$, Schematic of general habitus (ventral view) showing conventions used to measure specimens and location of vestigial legs (vl), dark-staining sclerites (sc), and bands of striated muscle (m); 1 , total length; $h$, head length; $n$, neck length; $t$, trunk length. Unlabeled arrows (top to bottom) indicate levels where head width, primary head protuberance width, neck width, trunk width, and trunk lobe width were measured, respectively; $B$, anterior of NSMT-Cr 14165 showing ventral (vp) and anteroventral (ap) protuberances, ventral view; $C$, same, lateral view; antennae $\left(\mathrm{a}_{2}\right) ; D$, same, dorsal view; $E$, antenna, note small basal seta $(\mathrm{s})$ and lateral tine (lt); $F$, vestigial legs; endopod (en), exopod (ex); $G$, caudal ramus. 


\section{ACKNOWLEDGMENTS}

We thank Kunio Amaoka, Kazuhiro Nakaya, and Mamoru Yabe (all Faculty of Fisheries, Hokkaido University, Hakodate) for allowing K.N. to use facilities and examine fish in the collection at Hokkaido University; Jeffrey Braswell (Dupont, Chattanooga) and Dupont's Fiber Engineering Technology Center Analytical Services for access to and assistance with SEM equipment; and the Southeast Aquatic Research Institute for general laboratory support. This study represents a portion of an undergraduate internship completed by J.W. at Southern Adventist University, Collegedale, Tennessee.

\section{Literature Cited}

Benz, G. W., and J. S. Braswell. 1998. Morphology of the deep-sea copepod Bobkabata kabatabobbus (Lernaeosoleidae: Poecilostomatoida) and amended diagnosis of Lernaeosoleidae. J. Parasitol. 84:109-113. Hogans, W. E., and G. W. Benz. 1990. A new family of parasitic copepods, the Lernaeosoleidae (Poecilostomatoida), from demersal fishes in the Northwest Atlantic, with a description of Bobkabata kabatabobbus n.gen., n.sp. and a redescription of Lernaeosolea lycodis Wilson, 1944. Can. J. Zool. 68:2483-2488.

Humes, A. G., and R. U. Gooding. 1964. A method for studying the external anatomy of copepods. Crustaceana (Leiden) 6:238240.

Huys, R., and G. A. Boxshall. 1991. Copepod evolution. The Ray Society, London.

Kabata, Z. 1979. Parasitic Copepoda of British fishes. The Ray Society, London.

Nelson, J. S. 1994. Fishes of the world, 3rd ed. John Wiley and Sons, New York.

Scott, W. B., and M. G. Scott. 1988. Atlantic fishes of Canada. Can. Bull. Fish. Aquat. Sci. 219:1-731.

Yabe, M. 1984. Malacocottus zonurus Bean. Page 330 in H. Masuda, K. Amaoka, C. Araga, T. Uyeno, and T. Yoshino, eds. The fishes of the Japanese Archipelago. Tokai University Press, Tokyo. 